\title{
Editorial
}

\section{The health of charged particle optics}

In 1980, a meeting was held in Giessen, the object of which was to bring together the members of the three major particle optics communities: electron optics, accelerator optics and mass spectrometer optics. The same basic equations and the same optical concepts are used in all these fields but before that meeting, there was little contact between them and hence much reduplication of effort. So successful was that first encounter that a further reunion was planned and thus the series of Charged Particle Optics (CPO) conferences was launched. Six years after that first meeting in Germany, which was largely the initiative of Hermann Wollnik, seconded by Karl Brown and myself, the Second International Conference on CPO met in Albuquerque, organized essentially by the American accelarator community. A third meeting was held in Toulouse in 1990, this time organized by the electron opticians, by which time the character of the meeting had begun to change, or rather to evolve. Its stated aim was still to bring together scientists using particle optics in very different domains with a view to sharing experience and, more concretely, sharing software and perhaps facilities. Some of the papers became more technical, however, and their interest beyond specialists in the same speciality was a little diminished.

Having met twice in Europe and once in the U.S.A., it was the turn of the other great centre of particle optics activity, Japan, whose scientists are extremely active in all the fields mentioned earlier. In October 1994, some 130 particle opticians met in Tsukuba to present their more recent findings and to discover what was new in related areas. A novelty at CPO4 was an afternoon devoted to CRT optics and the number of posters on all subjects was considerably greater than at any earlier CPO meeting. Indeed, CPO4 was different from its predecessors in many ways: for the first time, a substantial number of participants from Eastern Europe and the Asian mainland were able to attend, thanks in part to the ISF but also to the generosity of the Japanese sponsors. Another major difference was more original: the second evening ended with a force 7.9 earthquake, fortunately offshore, and we were able to see the effects of the ensuing tsunami in real time by means of charged particle optics on Japanese television.

In Tsukuba too, there was some tendency to present specialized developments, difficult to appreciate by members of the audience not belonging to the same speciality but on the whole, the spirit of the earlier conferences was maintained; it was generally felt that the best speakers were those who made a real effort to share their findings with the whole world of particle optics.

A very striking feature of ICEM13 here in Paris earlier this year was the resurgence of electron optics and the large number of important contributions in that field, with an afternoon of oral communications, a workshop and a vast poster session. This revival of electron optical activity was confirmed at CPO4, where there were not only many papers and posters of the highest interest but also a special symposium on aberration correction, generously supported by the Microbeam Analysis Committee of the Japanese Society for the Promotion of Science; this was largely dominated by the German efforts at microscope correction, already successful for the low-voltage scanning electron microscope and extremely promising for the high-resolution transmission instrument.

The meeting occupied four very busy days; there were of course no parallel sessions since the whole aim is to unite members of the different groups. The opening session was introduced by K. Ura, the conference president, after which the organizers of the first and third CPO meetings (H. Wollnik and myself) gave general talks on isotope separators and on some unsolved problems in the quicksands that separate geometrical and wave optics, respectively. We then pursued the various themes of the meeting in turn. The session on "Lithography and beam-testing instru- 
ments" was opened by a survey of the new miniature systems (H.W.P. Koops). In "Accelerators and beam transport", chaired by K.L. Brown, doyen of that subject, several papers dealt with the Lie-algebra-based methods (J. Irwin, M. Berz and A. Dragt) and there were also very interesting papers from KEK, the Tsukuba accelerator facility.

Tuesciay began with papers from London (X. Zhu and E. Munro), Brno (B. Lencová) and Madrid (G. Martinez and M. Sancho), which showed how highly perfected the software for field and trajectory calculation is today, and D. Carey gave a talk on "Neutrino optics", despite the fact that neutrinos are not charged particles and move in straight lines! The afternoon was occupied by the poster session, with about 70 posters on display and a tour of the KEK. And I must not forget the evening, for our Japanese hosts has arranged a superb banquet, something of a challenge to Western legs not accustomed to be folded at floor level in front of tables a few centimetres high. The quality and exotic nature of the food and the entertainment (in which a vendor of panacea made from the exudations of a giant frog, tested her wares on Alex Dragt) made up for any discomfort in the thighs.

Wednesday was devoted to microscopes and energy analysers and to CRT and image tubes. In the former, the paper by A. Takaoka on cathode lens optics was very impressive, as was the description by T. Kohashi et al. of a way of improving spin detection in the SEM. The theme of the afternoon session, CRT's, was a new departure for these CPO meetings and many of the speakers spent time explaining their preoccupations to those of us from other fields.

The final day opened with the session on mass spectrometers and mass separators, introduced by a model talk by A.G. Marshall et al. on ion optics for Fourier transform cyclotron resonance mass spectrometry. It ended, appropriately enough, with a paper by $\mathrm{M}$. Ishihara and $\mathrm{H}$. Matsuda on a very compact high-performance mass spectrometer. In the afternoon, a special symposium on "Aberration and its correction" consisted of six 30-minute papers of the greatest interest. $\mathrm{H}$. Rose described the gradual progress towards aberration correction, leaning heavily on the Darmstadt contribution, which showed clearly why so many attempts at correction have failed and led us to hope that the current endeavours will be more successful. He was followed by J. Zack of EMBL (Heidelberg), who described the successful correction of a low-voltage SEM. E. Munro then demonstrated convincingly the ability of present-day program suites to calculate secondary as well as primary aberrations. T.T. Tang discussed the aberrations of sectors and Wien filters, after which Y. Takai gave a dazzling display of aberration correction (for weakly scattering specimens) by focal averaging, in both the traditional and hollow-cone modes of operation of the TEM. Finally, T. Hanai, H. Yoshida and M. Hibino showed that foil lenses are capable of effecting some spherical correction in probe formation.

Altogether a successful meeting, with all the merits and benefits of a workshop atmosphere, which encouraged discussion at a high level. The Delft University Particle Optics Group led by P. Kruit agreed to organize the next CPO meeting in four years time in the Netherlands. Meanwhile, those of you who could not get to Tsukuba will be able to study the work presented in the Proceedings, to appear shortly as a special number of Nuclear Instruments and Methods in Physical Research, Part A.

\section{P.W. Hawkes}

\section{CEMES/LOE CNRS,} 29, rue Jeanne Marvig, 31055 Toulouse Cedex 